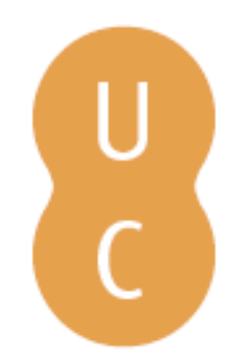

\title{
pommalina
}

\section{Reinhold Shneider e a ficção poética camoniana}

Autor(es): $\quad$ Carrington, Maria Cristina

Publicado por: Imprensa da Universidade de Coimbra

URL

persistente: URI:http://hdl.handle.net/10316.2/31146

DOI: $\quad$ DOI:http://dx.doi.org/10.14195/978-989-26-0569-2_30

Accessed : $\quad$ 26-Apr-2023 16:11:20

A navegação consulta e descarregamento dos títulos inseridos nas Bibliotecas Digitais UC Digitalis, UC Pombalina e UC Impactum, pressupõem a aceitação plena e sem reservas dos Termos e Condições de Uso destas Bibliotecas Digitais, disponíveis em https://digitalis.uc.pt/pt-pt/termos.

Conforme exposto nos referidos Termos e Condições de Uso, o descarregamento de títulos de acesso restrito requer uma licença válida de autorização devendo o utilizador aceder ao(s) documento(s) a partir de um endereço de IP da instituição detentora da supramencionada licença.

Ao utilizador é apenas permitido o descarregamento para uso pessoal, pelo que o emprego do(s) título(s) descarregado(s) para outro fim, designadamente comercial, carece de autorização do respetivo autor ou editor da obra.

Na medida em que todas as obras da UC Digitalis se encontram protegidas pelo Código do Direito de Autor e Direitos Conexos e demais legislação aplicável, toda a cópia, parcial ou total, deste documento, nos casos em que é legalmente admitida, deverá conter ou fazer-se acompanhar por este aviso.

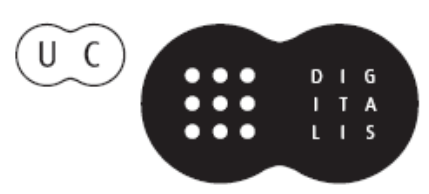




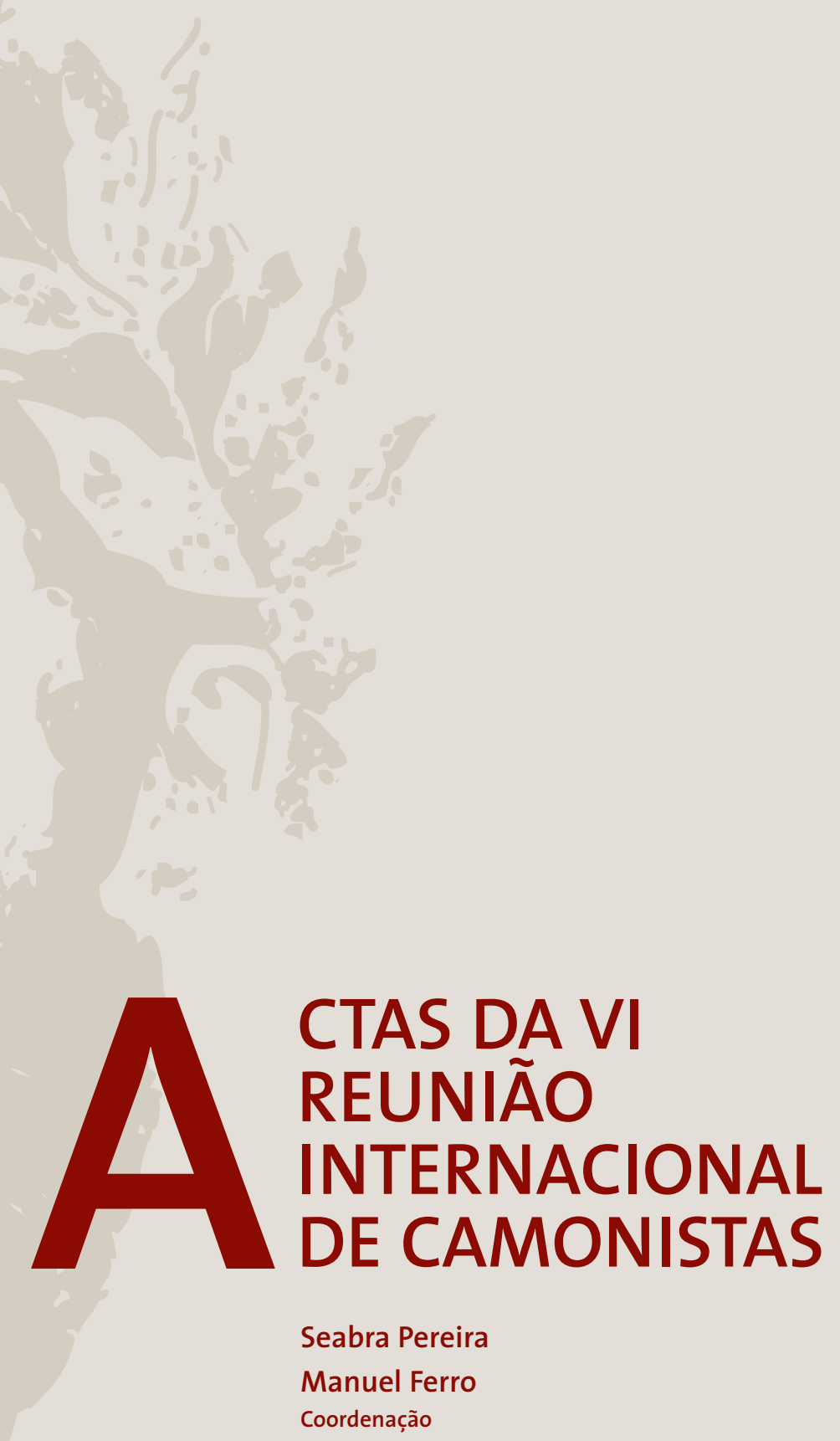




\section{Maria Cristina Carrington}

Universidade de Aveiro

\section{REINHOLD SCHNEIDER E A FICÇÃO POÉTICA CAMONIANA}

No ensaio histórico Das Leiden des Camoes oder Untergang und Vollendung der portugiesischen Macht (1930) [O sofrimento de Camóes ou a decadência e apogeu do poderio português], Reinhold Schneider apresenta o destino do povo português como o destino singular de um povo cuja missão histórica se cumpriu quando partiu para a descoberta de novos mundos e construiu um vasto e rico império. A grandeza e a glória então alcançadas a breve trecho se transformaram em perdiçáo e ruína, completando-se um ciclo trágico de ascensão e derrocada.

Nesta obra, a figura central é Camóes, o imortalizador da grandeza passada da pátria, o regenerador da catástrofe portuguesa do século XVI, na medida em que, com a sua epopeia, transformou e sublimou a história portuguesa imperfeita ${ }^{1}$. Camóes é, nesta obra, também apresentado como o representante do carácter e do destino do seu povo, como símbolo do sentir nacional, espelho da alma portuguesa.

Vejamos como Schneider se refere ao poeta numa carta de 4 de Fevereiro de 1930, dirigida à casa editora Merlin, de Baden-Baden, em que o lusófilo propóe a publicação da obra:

"Im Camóes suchte ich die portugiesische Katastrophe im 16. Jahrhundert darzustellen. Der Dichter Camóes ist als endgültiger Repräsentant und Rechtfertiger des nationalen Charakters und Schicksals behandelt" (apud Schmitt, 1973, p. 68).

[Em Camóes eu procurei descrever a catástrofe portuguesa do século XVI.

O poeta Camóes aparece como o representante acabado, como aquele que justifica o carácter e o destino nacionais].

${ }^{1}$ Cf. as palavras de Schneider no último capítulo da obra Das Leiden des Camoes oder Untergang und Vollendung der portugiesischen Macht: "Alles was in Portugal geschah, bekommt allein von Camoes seinen Sinn, und selbst wenn es groß war, so wird es durch ihn noch größer» (C., p. 165) [Tudo o que aconteceu em Portugal só adquire sentido com Camóes, e mesmo que tenha sido algo de grandioso mais grandioso fica ainda através dele]. 
Alguns meses mais tarde, submetendo de novo o texto a apreciação editorial, desta feita da casa editora Hegner, Schneider acentuará esta ideia, dizendo que no ensaio histórico Camoes. Der Untergang der portugiesischen Macht [Camōes. A decadência do poderio português] $]^{2}$ a figura do poeta foi concebida como protótipo do carácter português, sendo sobretudo a sua lírica que revela tal qualidade:

"Im Mittelpunkt meiner Arbeit steht der Dichter Camoes, der größte Epiker der modernen Zeit. Er wird jedoch ausschließlich als Repräsentant des portugiesischen Charakters und des portugiesischen Schicksals, nicht als eine Erscheinung der Literaturgeschichte behandelt. (...) Als Vertreter des Volkscharakters erweist er sich in seiner Lyrik, in der eine nur in Portugal existierende Form der Liebe gestaltet ist: die passive Leidenschaft. (...) Die Lyrik des Camoes, welche die sonderbarsten und subtilsten psychologischen Probleme berührt, wurde niemals auf eine spannende, weiten Kreisen verständliche Art behandelt."3

[No centro do meu trabalho está o poeta Camóes, o maior épico da era moderna. Trato-o, no entanto, exclusivamente, como representante do carácter português e do destino português, não como uma figura da história literária. (...) É na lírica que se revela como representante do carácter do seu povo, naquela forma de amor que só em Portugal existe: a paixão passiva.(...) A lírica de Camóes, que toca os mais singulares e subtis problemas psicológicos, nunca foi tratada de forma interessante e inteligível a círculos alargados.]

E mais adiante:

“(...) Von frühester Kindheit an ist Camoes der Leidenschaft unterworfen, der portugiesischen Leidenschaft, in der ein tiefes Verlangen nach Leiden und Verderben verborgen ist." 4

[Desde a mais tenra idade Camóes é vítima da paixão, da paixão portuguesa, em que se esconde um desejo profundo de sofrimento e de ruína].

Luís de Camôes é, portanto, segundo Reinhold Schneider, o retrato vivo do homem português, do homem que se deixa dominar pela paixão passiva, pela dor e pelo sofrimento, e que vive na ânsia de destruição.

Baseando-se numa leitura fortemente biografista da obra camoniana, a caracterização do Poeta, iniciada no capítulo "Der Dichter" [O poeta], o terceiro do ensaio histórico,

${ }^{2}$ O título proposto por Schneider no manuscrito era Camoes. Der Untergang der portugiesischen Macht. O editor, Jakob Hegner, decidiu alterar o título e, sem consulta prévia do autor, publicou o texto com o título Das Leiden des Camoes oder Untergang und Vollendung der portugiesischen Macht.

${ }^{3}$ Manuscrito existente no Arquivo Reinhold Schneider na Badische Landesbibliothek Karlsruhe, RSA, p. 202.

${ }^{4}$ Idem, ibidem. 
é levada a cabo num permanente entretecimento entre a obra lírica e as circunstâncias e vicissitudes que rodearam o nascimento e juventude do autor.

Esta visão schneideriana, muito provavelmente na senda das leituras biografistas propostas pela crítica literária do romantismo e positivismo alemães, é, a meu ver, também o produto de uma necessidade pessoal do próprio escritor germânico, que, ao ler os textos líricos de Camóes se revê nas vivências que o sujeito poético camoniano confidencia.

Quando percorremos o acima referido capítulo terceiro da obra Das Leiden des Camoes oder Untergang und Vollendung der portugiesischen Macht, fica-nos a impressão de que, nomeadamente no segundo subcapítulo, ou seja, na sequência intitulada "Traurigkeit und Leidenschaft" [Tristeza e paixão], há um exagero na descrição do amor, da paixáo, do sofrimento, da tristeza, da saudade, "do gosto de ser triste», que perpassam nos poemas de Camóes. É como se assistíssemos a um rodopiar de ideias e sentimentos, que em espiral se repetem e alargam, num movimento circular só interrompido pelo breve interlúdio histórico em que se alude à chegada dos Jesuítas ao nosso país, durante o reinado de D. Manuel, e ao estabelecimento da Inquisição no tempo de D. João III (C., pp. 67-69) 5 .

A repetição, a meu ver excessiva, das emoçôes e sentimentos expressos pelo eu lírico camoniano denota a leitura empática que considero existir por trás da caracterização do poeta feita por Schneider. Curiosamente, ao analisar a lírica de juventude do autor alemão ${ }^{6}$, verifiquei que nela se pressentem ecos das suas vivências e experiências individuais, ao mesmo tempo que se pode divisar uma evolução análoga àquela que ele atribuiu ao lírico português.

Os testemunhos de alguns que privaram com o autor ${ }^{7}$, as apreciaçóes do próprio Schneider sobre estes sonetos dos primeiros anos (cf. Schmitt, 1973, pp. 77-78) e as indicaçóes dadas por Elizabeth Schmidt na sua dissertação de doutoramento sobre textos ainda inéditos e sobre a sua ordenação temática e cronológica ${ }^{8}$ confirmaram as

\footnotetext{
${ }^{5}$ Estes breves comentários históricos foram claramente influenciados pela leitura da obra de Heinrich Schäfer, Geschichte von Portugal, 3. Bd, Hamburg, Friedrich Perthes, 1859, pp. 9-10 e 355 s.

${ }^{6}$ Trata-se de um vasto conjunto de sonetos, a maioria dos quais só foi publicada postumamente. Grande parte destes sonetos, que Schneider apresentou aos amigos (1928, 1929) e depois à casa editora Insel (1930), não conseguiram publicação. Só em 1939 a mesma editora Insel oferece aos leitores um volume de sonetos, Sonette, em que se incluíam alguns dos textos dos primeiros anos (1927-1929). Uma outra edição mais completa foi depois publicada em 1954 (Hegner) com o título Die Sonette von Leben, dem Glauben und der Geschichte. Muitos dos sonetos escritos em finais dos anos vinte, princípio da década de trinta, e até há pouco tempo guardados no espólio do autor em Karlsruhe, surgiram em 1981, de novo na Insel, numa edição das obras completas levada a cabo pela Reinhold Schneider-Gesellschaft.

${ }^{7}$ Refiro-me sobretudo a Maria van Look e às suas interessantes notas em Jahre der Freundschaft mit Reinhold Schneider. Aus Tagebuchblättern von Maria van Look, Weilheim/Oberbayern, Otto Wilhelm Barth Verlag, 1965 e a Jochen Klepper, Unter dem Schatten Deiner Flügel. Aus den Tagebüchern der Jahre 1932-1942, hrsg. Hildegard Klepper, Auswahl, Anm. u. Nachw. v. Benno Mascher, Stuttgart, Deutsche Verlags-Anstalt, 1956.

8 A tese de doutoramento de Elisabeth Schmidt, Tragik und Kreuz. Versuch einer Interpretation der Lyrik Reinhold Schneiders, Wien, 1963, embora já desactualizada nas informaçôes que fornece quanto aos textos não publicados, e apesar de apresentar uma leitura biografista dos sonetos schneiderianos, é ainda um importante elemento de referência.
} 
minhas impressôes, revelando que poderia estabelecer-se uma correspondência entre a organização temática dos poemas incluídos no volume Tragische Welt (1931), dividido em três partes, [Mundo trágico] — I - "Schwermut" [Melancolia]; II - "Durchbruch" [Viragem]; III - “Die Tat" [A acção] — e o conteúdo do capítulo "Der Dichter" [O poeta], em Das Leiden des Camoes, também ele tripartido nos subcapítulos, "Geburt" [Nascimento]; "Traurigkeit und Leidenschaft" [Tristeza e paixão]; "Die Überwindung" [A superação]. Parecia-me possível traçar eixos de ligação entre a primeira parte do livro de sonetos "Schwermut" e os dois subcapítulos do ensaio "Geburt" e "Traurigkeit und Leidenschaft" e, no sentido inverso, entre o terceiro subcapítulo "Die Überwindung" e as duas últimas partes "Durchbruch" e "Die Tat".

Ao paralelismo estrutural dos dois textos corresponderia, pois, um paralelismo na trajectória do eu lírico de Schneider e da figura de Camóes no ensaio histórico. Em ambos os casos se detectava um percurso vital idêntico, um evoluir de uma situação de acabrunhamento e de melancolia para um estádio de superação.

Examinemos os textos mais de perto.

Grande parte dos sonetos coligidos em Tragische Welt (1931) datam de 19271930 e são peças que parecem reflectir o modo de sentir de Schneider nestes anos de desmoronamento e de abalo interior. Os poemas, segundo interpretação do próprio autor expressa na introdução do referido volume, constituem a expressão do seu desespero, da sua estranheza em relação ao mundo e aos outros, do seu mal-estar e insatisfação pela monotonia do quotidiano, do seu sofrimento pelo desaire amoroso:

"Das Ganze bezeichnet eine Entwicklung und erhebt durchaus keinen Anspruch auf schöne Einzelstücke; die Linie, die Richtung entscheiden: nicht die Kunst. So widersprechen sich die Stücke des ersten und des

dritten Teils auf das heftigste; aus allem Nein wird ein Ja; freilich ein unbequemes. Die Sonette bezeichnen: Eintritt in die Welt; Durchgang durch

die Welt; Abschied von der Welt; sie gehen von der Verzweiflung bis zum Glück, und das heißt nichts anderes: als von der Ungewißheit über die eigene Aufgabe bis zur Erkenntnis und Erfüllung der Mission. (...) Die

höchsten und heftigsten Stunden meines Lebens sind darin: die schwersten Gewichte der Schmerzen; die düsterten Einsamkeiten; das tiefverhängte Zwischen- und Schicksalsspiel meiner Liebe; die ersten Blitze; ferne vielfältige Landschaften und der Abschied von allem. Ein großes

Stück Welt wird aufgenommen, aber nicht festgehalten; es treibt weiter;

und was erst noch eine mühselige Reise war auf der Erde, wird am Ende zum Flug, der es noch eiliger hat als die Wolken. Im Ganzen: das

schwerste Gewicht, das ich auf fünfzig Seiten, in neunhundert Zeilen bringen konnte. (apud Schmitt, 1973, p. 78)

[O conjunto significa uma evolução e não tem quaisquer pretensões a bonitas peças únicas; o que decide é a linha, o rumo, não a arte. Assim, as peças da primeira e das terceira partes contradizem-se violentamente; todo um não se transforma num sim; decerto um sim incómodo. Os sonetos significam: entrada no mundo; passagem pelo mundo; despedida do mundo; vão do desespero à felicidade e isto não quer dizer mais nada do que a passagem 
da incerteza da própria tarefa para o reconhecimento e cumprimento da missão. (...) As mais altas e mais intensas horas da minha vida estão ali: as mais pesadas cargas da dor; as mais sombrias solidóes; o interlúdio fatal do meu amor tão marcado pelo destino; as primeiras fulminaçôes; longínquas paisagens multímodas e a despedida de tudo. Um grande pedaço de mundo é apreendido, mas não retido; não se detém e aquilo que ainda agora era uma penosa caminhada pela terra, acaba por transformar-se em voo mais apressado ainda do que as nuvens. Em suma: o mais pesado de todos os fardos, que eu, ao longo de cinquenta páginas e novecentos versos, consegui carregar].

Desde muito cedo paira sobre o escritor alemão uma "unerklärliche Traurigkeit» (VT, 18) [inexplicável tristeza], um acabrunhamento e uma amargura, fruto de um pendor depressivo e melancólico que Schneider considerava herança paterna.

Em dois dos seus sonetos, ambos com a epígrafe An meinen Vater (1928) [A meu pai], ${ }^{9}$ encontramos a expressão do amor, do respeito e da veneração que Schneider nutria pelo seu progenitor e sentimos a sintonia espiritual entre pai e filho. Reinhold Schneider pressentira e compreendera o pessimismo e a desesperança que tinham levado o pai ao suicídio, e aceitava o mal-estar existencial como se de uma herança genética se tratasse:

"Der Schwermut Erbe ward mir übermacht,

Es ist mein Untergang und ist mein Lohn;

Wohl fühlte ichs in frühen Tagen schon,

Doch kommts aus frühern, aus des Anfangs Nacht.

Du hast als letzter mir die schwere Fracht

Der Väter auferlegt zu Not und Fron,

Ich will sie tragen, bis zuletzt dein Sohn

Doch sei in mir das Leid zur Ruh gebracht.” (L., p. 10)

[Calhou-me em herança a melancolia

Minha perdição e minha recompensa

Bem a senti já em verdes anos

Mas vem de mais atrás, do começo da noite.

\footnotetext{
9 Surgem algumas dúvidas quanto às datas de produçấo dos sonetos com a epígrafe An meinen Vater. Schmitt e Scherer (Schmitt, 1973, pp. 52-53) consideram que os dois textos inseridos no volume Tragische Welt (1931) datam de 1926, tendo sido apenas o segundo, ou a segunda parte, como lhe chamam, publicada na edição Die Sonette von Leben und Zeit, dem Glauben und der Geschichte de 1954. Constato, no entanto, que, neste segundo soneto, as duas estrofes do meio apresentam diferenças em relaçáo às inicialmente escritas em Tragische Welt, (cf. Schmitt, 1973, p. 53 e cf. a edição de 1954, p. 23); é esta última versão que é depois transcrita na edição das obras completas, em 1981 (cf. nota 6), com a data de 18.1.1928. O primeiro soneto «Ich sehe Dich in Deinen letzten Jahren» é também inserido na edição da Reinhold Schneider-Gesellschaft, mas uma vez mais as datas não coincidem com as informaçôes anteriores, pois a data indicada como data de produção é, de novo, 18/19.1.1928.
} 
Tu último me impuseste a grave carga

Dos pais, marca de dor e escravidão

Vou carregá-la, teu filho até ao fim

Mas que em mim a dor repouse enfim.]

A vida do jovem Schneider é então marcada por circunstancialismos que lhe são simultaneamente inatos e extrínsecos. Estigmatizado pela insatisfação e pela melancolia ${ }^{10}$, dominado por uma crise existencial e pelas próprias convicções do carácter trágico da vida, deixa-se arrastar pela angústia e deseja a morte ${ }^{11}$.

O percurso de Camóes, tal como nos é transmitido pelo autor do ensaio histórico, parece apresentar pontos de contacto com o caminho percorrido pelo eu lírico schneideriano. Parafraseando a célebre canção "Vinde cá meu tão certo secretário"12 e seguindo a visão biografista que adoptou, Schneider vai descrever a hora do nascimento do poeta como um momento marcado por terríveis vaticínios, em que a conjugação dos planetas anunciava o fim do mundo (Vms, p. 61; C., p. 49). Camóes é então apresentado como um ser marcado por um destino trágico, sendo a morte da mãe, ao dá-lo à luz, o começo da tragédia. A substituição do seio materno pelo seio de uma ama de leite, caracterizada como "humana fera tão fermosa» (Vms., p. 62; C., pp. 53, 63), vai fazer com que ele beba desde o berço o leite amargo da tristeza, o «veneno» (Vms., p. 62; C., p. 53) do amor-melancolia. Segundo Schneider, toda a existência do poeta, transposta para esta canção de feição autobiográfica, vai ser marcada pelos tormentos, desatinos e misérias, que foram prenunciados ao nascer (C., p. 50) e Camóes viverá na desesperança e no sofrimento, regozijando-se com a ideia do fim.

O eu lírico camoniano e a persona poética dos sonetos de Schneider manifestam portanto uma proximidade nos estigmas que receberam à nascença e uma comunhão dos estados de alma dominantes, vivendo ambos uma relaçáo de contiguidade com a morte. Revelam ainda uma total incapacidade para serem felizes, sentindo ambos o amor como uma experiência trágica.

O relacionamento de Reinhold Schneider com Anna Maria Baumgarten, encetado nos anos de desespero de Dresden e, no início, cingido a entusiasmadas discussóes intelectuais sobre literatura e filosofia, rapidamente se tornou em atracção mútua, que os vinte e dois anos de diferença na idade vieram dificultar ${ }^{13}$. Para além de um declarado sentimento de

${ }^{10}$ Leia-se o poema de 1923 ? "An die Melancholie” (L., pp. 374-375) [À melancolia], ou o soneto «Der «Die Last» [A carga] de 9 e 10.1.1929 (L., p. 258).

${ }^{11}$ Cf. o soneto de 1928 "An den Tod" [À morte] (L., pp. 228-229), ou um outro de 26.1.1929 «Das neue Gesezt» [A nova lei] (L., pp. 258-259). Leia-se o que o autor diz no seu escrito autobiográfico Verhüllter Tag, VT, pp. 47-48. Veja-se ainda como mais tarde recorda esta ânsia de morte, num dos ensaios coligidos em Schicksal und Landschaft, Hg. Curt Winterhalter, Freiburg, Basel, Wien, Herder, 1960, p. 378.

12 Em texto, a canção "Vinde cá meu tão certo secretário" será indicada com a sigla Vms, seguida dos versos a que me estou a referir. As referências à lírica camoniana são feitas segundo a edição da Lírica Completa I,II,III, prefácio e notas de Maria de Lurdes Saraiva, Lisboa, Imprensa Nacional - Casa da Moeda, 1980.

13 No seu Diário, a 22 de Junho de 1930, Schneider diz explicitamente: «Es ist wirklich wahr, daß wir [Maria und ich], läge das Verhängnis der Jahre nicht zwischen uns, hätten glücklich werden können" [É mesmo verdade que nós [a Maria e eu], se náo fosse o destino/fatalidade dos anos, poderíamos ter sido felizes], Tagebuch. 1930-1935, Redaktion und Nachwort v. Joseph Rast, Frankfurt, Insel, 1983, pp. 74. 
gratidão em relação a Anna Maria, que o salvara da morte quando da sua tentativa de suicídio em 1922, Schneider confessa sentimentos de amor e paixáo por aquela a quem veio a chamar de "Gefährtin seines Lebens» [companheira da sua vida] ${ }^{14}$.

Se percorrermos as cartas trocadas entre os anos de 1923 e 1928, encontramos reflexos de uma experiência amorosa difícil e amargurada ${ }^{15}$, marcada principalmente pelas sombras do tempo, pela "Tragödie des Alters» (Tgb., p. 75) [tragédia da idade].

Os testemunhos do Diário, na década de trinta, confirmam o estado de espírito do autor nesta época, pois como nos diz, logo nas primeiras páginas, a 25 de Maio de 1930:

Maria liebte ich wirklich; die einzige Epoche der Vergangenheit, die mich mit Wehmut erfüllt, ist diese erste Zeit unseres Zusammenseins, als ich wie ein Träumender durch die Straßen ging. (...) Ohne es zu wollen, weil sie mußte, weil es nicht anders ging, hat sie selbst die Liebe erstickt, die von

Anfang an unterm Schatten der Zeit lag (...); ich hänge sehr an ihr, ich verehre sie fast, ihre Anteilnahme ist mir unentbehrlich, aber ich bin unwiderruflich allein. Ich kann nicht ein Wort von Liebe schreiben;

es wäre Lüge.” (Tgb., pp. 11-12)

[Eu amava verdadeiramente Maria; a única época do passado que me enche de saudade são aqueles primeiros tempos em que convivemos, quando eu andava pelas ruas como um sonhador. (...) Sem que fosse essa a sua vontade, porque tinha de agir assim, porque não podia ser de outra maneira, ela mesma sufocou aquele amor, que, desde o início, viveu sob a sombra do tempo; estou muito ligado a ela afectivamente, quase a adoro, o interesse dela é-me essencial, mas estou irremediavelmente sozinho. Não posso escrever uma palavra de amor; seria mentira].

A hipertensão vivencial destes anos vai projectar-se em grande parte dos seus sonetos, textos cheios de dramatismo psicológico, que apontam para a difícil relação amorosa com A. M. Baumgarten. O soneto "Mir bebt das Herz, wenn ich dich wandeln sehe" (13-14.8.1927) [Estremece-me o coração quando te vejo andar], ou "Wie kann, was also früh begonnen, enden?" (1927), [Como pode acabar aquilo que tão cedo começou] ou ainda os quatro sonetos intitulados Zeit und Liebe (7.5.1927; $1.1 .1928 ; 13.1 .1928 ; 14.1 .1928$ ) [Tempo e Amor], são a expressão da jovem paixão do autor, que transpóe para o discurso lírico o sofrimento e a depêndencia emocional que sentia em relação a Anna Maria.

Ensombrada pela diferença de idade, a atracção amorosa cede lugar ao desapego, à renúncia e o jovem poeta afasta-se, entregando-se ao sofrimento e entusiasmando-se

\footnotetext{
14 Schneider, no seu testamento, chamou a Anna Maria Baumgarten «die Gefährtin seines Lebens» e designou-a herdeira de todo o seu espólio literário, cf. Maria van Look, Jahre der Freundschaft mit Reinhold Schneider, p. 33.

15 Cf. as numerosas referências às cartas nâo publicadas entre Reinhold Schneider e Anna Maria Baumgarten, nos estudos de Cordula Koepke, Reinhold Schneider: eine Biographie, Würzburg, Echter, 1973, sobretudo pp. 27-29, 32-33 e de Rolf Willaredt, Reinhold Schneider und Nietzsche. Reinhold Schneiders 'Tagebuch 1930-1935' unter dem Leistern Friedrich Nieztsche, Frankfurt, Berlin, Bern, New York, Paris, Wien, Peter Lang, 1993, sobretudo p. 89, nota 41 e pp. 90-91.
} 
com a própria dor. A 1 de Junho de 1930, em Madrid, longe da Alemanha e de Anna Maria, regista no seu Diário:

"Maria schreibt, sie gedenkt mit Wehmut des Tages, an dem wir uns vor acht Jahren getroffen haben. Vielleicht wünscht sie diese Zeit und die Jahre, die ihr folgten zurück.(..) Nein, ich wünsche nichts zurück. Mag jetzt auch in der Hölle leben; (...) Und doch: sie liebt; sie ist verlassen; sie tut mir unendlich leid. - Ich liebe nichts und niemand; das ist vielleicht noch schlimmer. Es ist sicher, daß ich sie sehr geliebt habe; ich hätte für sie sterben können. Das Wunderbare war: ich liebte in ihr den Schmerz". (Tgb., p. 31)

[Maria escreve que pensa com saudade no dia em que, há oito anos, nos encontrámos. Talvez ela deseje que regressem esse tempo e os anos que se lhe seguiram. (...) Não, eu não desejo que nada regresse. Mesmo que eu agora viva num inferno. E, contudo: ela ama, está abandonada; faz-me uma pena infinita. -Eu não amo nada nem ninguém, talvez seja ainda pior. Não há dúvida que a amei muito; poderia ter morrido por ela. O que foi estranho foi que nela eu amei a dor].

A 19 de Janeiro do ano seguinte (1931), reflectindo sobre as suas emoçóes, conclui: "Vielleicht kann ich nur dort lieben, wo ich verzichten muß. Denn im Grunde ist es gerade das, was ich in der Liebe suche: der stärkste Verzicht». (Tgb., p. 255) [Se calhar só posso amar quando tenho de renunciar. Porque no fundo é exactamente isso que eu procuro no amor: a mais intensa das renúncias].

Caminhos similares teria percorrido Camôes, diz-nos Schneider, num destino de sofrimento, de tristeza e de renúncia, não obstante na biografia do poeta apresentada pelo lusófilo a imagem da amada e a vivência amorosa serem de carácter diferente. Continuando o processo de transposição para a vida real daquilo que o sujeito poético da lírica camoniana confidencia, Schneider apresenta Camóes desde cedo ferido pela seta envenenada de Cupido, vivendo dominado pelo coração. A sua paixão impossível por uma jovem (Catarina de Ataíde), descrita à luz da lírica camoniana, como a imagem perfeita do eterno feminino, ou seja: «(..) kein Abbild, sondern (...) das Urbild» (C., p. 59) [não cópia, mas arquétipo], é apontada como a principal causadora da saudade e da dor (cf. C., pp. 59-60). O amor de Camóes, segundo o lusófilo alemão, um amor descomedido, mescla de paixão e tristeza, "Traurigkeit und Leidenschaft", em que se cultiva «o gosto de ser triste» (Vms., p. 65; C., p. 79), arrasta para a destruição e para o aniquilamento, nada mais restando ao poeta português do que a realização no sofrimento e na renúncia. "Das Maß des Leidens ist das Maß der wachsenden Vollkommenheit» (C., p. 67) [A medida do sofrimento é a medida da crescente perfeição], diz Schneider a propósito do amor camoniano, que encontrou espelhado nas suas cançóes, elegias, odes, redondilhas e sonetos ${ }^{16}$.

\footnotetext{
${ }^{16}$ Poderia registar aqui o cotejo sistemático dos textos de Camões que constituíram ponto de referência para Schneider - o que vai ao encontro da leitura biografista que venho a referir. Deixo apenas uma enumeração das ocorrências mais frequentes: a canção "Vinde cá meu tão certo secretário"; a canção "Junto
} 
O eu lírico camoniano funciona pois como modelo de identificação para o jovem autor alemão, parecendo que a via escolhida é a do pessimismo, do acabrunhamento e da tragédia. Avizinhava-se, porém, o momento da viragem, quando, com a leitura das obras do filósofo espanhol Miguel de Unamuno ${ }^{17}$, Schneider descobre um novo caminho.

Influenciado pela máxima unamuniana: «No, no nada de vivir al dia; hay que vivir a los siglos» (AyV., p. 137), Schneider toma consciência de que a única forma de resistir ao trágico e à decadência que dele se tinham apoderado está no entretecimento entre o Eu e a História, ou seja, na assunção de um estatuto de escritor-historiador ${ }^{18}$. Alcançaria desta forma a superaçáo da sua tragédia pessoal e conseguiria a realização numa dimensão supra-individual.

Volta-se então para a Península Ibérica, para Portugal, e redescobre Camóes, o representante máximo da nação, que com o seu poema épico transfigurou e sublimou a história portuguesa imperfeita. Numa nota biográfica de 12 de Fevereiro de 1931 descreve esse momento decisivo e refere a dado passo:

“(...)durch einen Aufsatz Unamunos über Coimbra wurde ich auf Portugal aufmerksam. (...)ich ging weiter zurück und ahnte das Schicksal des Camóes. Inzwischen hatte ich die tragische Wirklichkeit in mir selbst begriffen; ich sah, daß mein Leben, wenn es nicht verneint werden sollte, gelebt werden mußte von innen mit allen Konsequenzen. Mit einer Darstellung des portugiesischen Wesens bot sich mir zum ersten Mal die Möglichkeit, eine Gesamtheit zu umschreiben; im Erfassen eines relativ eindeutigen Schicksals an das Gesetz der Leistung und des Untergangs zu rühren; eine Katastrophe zu deuten.” (apud Schmitt, 1973: 32)

[(...) foi um ensaio de Unamuno sobre Coimbra que chamou a minha atenção para Portugal. (...)Recuei um pouco e pressenti o destino de Camóes. Entretanto, eu compreendera no meu íntimo a realidade trágica; vi que a minha vida, se não devia ser negada, tinha de ser vivida, a partir de dentro, com todas as consequências. Ao apresentar o modo de ser português ofereceu-se-me pela primeira vez a possibilidade de dar forma a uma totalidade; de ao apreender um destino relativamente claro aflorar a lei da realização e do declínio, de interpretar uma catástrofe].

de um seco, fero e estéril monte"; a elegia "O poeta Simónides, falando"; a elegia "Aquele mover de olhos excelente"; a ode "Fogem as neves frias"; o soneto "O culto divinal se celebrava"; o soneto "Aquela triste e leda madrugada".

17 O papel decisivo que Miguel de Unamuno teve na vida de Reinhold Schneider é afirmado pelo próprio Schneider em alguns dos seus escritos autobiográficos. Cf. VT., pp. 51-53, cf. também, "Lebensringe" (1953), Erfüllte Einsamkeit, Freiburg, Basel, Wien, Herder, 1963, pp. 22-23. Vd. ainda a carta de Schneider a Unamuno de 13 de Dezembro de 1926, apud Schmitt, 1973, p. 54. As obras que mais influenciaram o jovem Schneider foram Del sentimiento trágico de la vida en los hombres y en los pueblos (1913) e Andanzas $y$ Visiones españolas (1922). Esta última obra surgirá em texto com a sigla AyV.

${ }^{18}$ Leiam-se as palavras do autor que relembra em Verbüllter Tag: «Das Ich als Ziel und Sinn ist tödlich; das hatte ich erfahren. Das Ich wird erst tragbar, wenn es eingewoben ist in die Geschichte» (VT., p. 54) [O Eu como objectivo e sentido é mortífero; isso tinha-o eu experimentado. O Eu só se torna suportável quando é entretecido na História]. 
Consumada a viragem ("Durchbruch"), o jovem autor, cujo eu lírico dos sonetos apresentara, também, na última sequência - "Die Tat" - a passagem do "não para o sim», tem agora um novo modelo existencial e identificador, o Camōes épico. Paradigma da superação da decadência através da produção estética ("Die Überwindung") [A superação], o épico português dá a Reinhold Schneider o ânimo de que necessitava para lutar contra o "conflito irreconciliável» (VT., p. 52) que o acabrunhava e tolhia. Libertando-se dos seus desassossegos individuais entrega-se à nova tarefa, à luta apaixonada com o tempo, à sua vocação de escritor historiográfico e poético, conseguindo assim, nas suas próprias palavras, a salvação:

"Der Sinn des Untergangs ist: daß ein Dichter die Grabschrift schreibt. Ich fühle die Stunde aufgehen [1928], da die Epitaphe geschrieben warden mußten. Das war noch ästhetische Wertsetzung, aber doch eine Mittelstellung vom Persönlichen zum Überpersönlichen, ein Übergang,

für mich eine Rettung "(VT: 54).

[O sentido da decadência é que seja um poeta a escrever o necrológio. Sentia nascer a hora [1928] em que se deviam escrever epitáfios. Ainda era apreciaçáo estética, mas já se tratava de uma posição intermédia no caminho do pessoal para o suprapessoal, de uma transição, para mim de uma salvação].

Em suma, podemos concluir que existe uma relação de identificação entre Schneider e Camóes. No entanto, se no início é o poeta lírico que serve de modelo existencial identificador para o jovem autor de sonetos, no final o modelo adoptado pelo autor alemão é o do Camóes épico, o poeta-artista cuja missão é a de, com a sua obra (com a sua epopeia), regenerar a história nacional. 